\title{
Multilevel Security Biometric Authentication Locking System Using Arduino UNO
}

\author{
Anirudh $\mathrm{R}^{\mathrm{a}, 1}$, Chandru $\mathrm{V}^{\mathrm{a}}$ and Harish $\mathrm{V}^{\mathrm{a}}$ \\ a Department of Engineering, Rajalakshmi Engineering College
}

\begin{abstract}
The main aim of our project is to implement the door lock system using the fingerprint sensor. There are many modern locks that replace the regular locks due to the high security, while we use this we are able to both lock (or) unlock the door lock using the fingerprint sensor. You are not supposed to carry the bundle of keys wherever you go, so that we can implement this idea and for the high security too. The possibilities of threats occurring in regular locks is less compared to the wireless biometric lock (i.e.) modern lock. Only a particular person can open the door lock (or) unlock it. It is not like the regular lock means if X person opening the lock using a key means the lock will release on its own. In modern lock there is no possibility that only the developer will open it, if someone wants to access using smartphone we should get verification from the user by getting the OTP and login the app.
\end{abstract}

Keywords. Fingerprint sensor, Biometric Lock, Smartphone, Application.

\section{Introduction}

Security is a primary concern in today's busy world and humans cannot give security to their belongings each and every time. If the door can easily be opened then the belongings of an individual can easily be stolen. For the security purpose the humans invented modern technologies. At early stages, a door with a physical key to lock is used which is considered to provide less security and after the development of technology modern locks have been innovated. These locks can be locked or unlocked by the user without the use of a physical key. The most easy and secure system that is being used is the fingerprint recognition system in which a fingerprint of an individual cannot be matched with others. The system uses a microcontroller which is used to control other devices in the system. The HC-05 Bluetooth module is used for transparent wireless serial connection setup. The system has a multi level of security compared to other systems. At first the user must sign up by providing the required details and then their fingerprint must be enrolled to the database so that the system can grant access to the user to unlock the door. Among other available biometric traits fingerprint proves to be the best traits that provides high security, good mismatch ratio and reliability.

\footnotetext{
${ }^{1}$ Anirudh R, Department of Engineering, Rajalakshmi Engineering College, Chennai.

E-mail: anirudh.r.2017.it@ rajalakshmi.edu.in
} 


\section{Related Works}

The literature review works help to generate and expose skills of searching for information from a variety of sources. These skills are very important to solve the problems encountered or will face in the future. IoT has been applied in various researches in smart home technology to remotely control and monitor various appliances [1]. Some research also focuses on efficiency to lower power consumption [2]. Some of the research, like the following, have been done about security systems. Agbo David.O proposed a smart home controller that uses the Bluetooth in an Android device to control the operation of an automated security door system [3]. Research conducted by Rahul Saikia, Malabika Sharma, Amlanjyoti Gogoi and Dibya Jyoti Bora describes a system which will control doors by using smartphones [4]. This system needs a camera, micro controller AT89S52, Bluetooth module HC-05, Arduino Uno and R305 fingerprint sensor. Whenever a person stands in front of the camera, it will detect and send image to the mobile device. User can control the door by using smartphone.

Piash Paul et al. proposed Smart Door Lock Using Fingerprint Sensor [5]. In this system, the user will enter a fingerprint in the fingerprint scanner which is connected to the door latch through the microcontroller. After scanning the print, the system runs its database and looks for a match. If any match is found, the latch opens and thus the door gets unlocked. The drawback in this project is that a person's finger changes sizes or form/pattern over time and the fingerprint scanner does not take this into consideration. Venkata Rao,et.al proposed Smart Door Unlock System using Fingerprint to detect intruder [6]. A micro controller is used to enable the door opening or closing if the matching between scanned data and the already existing data is correct. Comparison is done inside the fingerprint module itself and its output is given to the micro controller. Result is displayed in an LCD display whether the user is authorized or not. The limitations is that It doesn't take a lot for the thumb scanner door lock to not recognize your fingerprint due to reasons such as oily fingers, or a dirty fingerprint scanner.

A research conducted by Tennyson and Amuda describes a system which will control doors by fingerprint sensor [7]. A fingerprint locker system using a micro controller uses a fingerprint recognition system as a process of verifying the fingerprint image to open the electronic lock. This research highlights the development of fingerprint verification systems using Arduino 1.6.3. Verification is completed by comparing the data of authorized fingerprint image with incoming fingerprint image. The incoming fingerprint image will first go through the extraction and filtering processes through which the information about it is obtained. Then the information of the incoming fingerprint image will undergo the comparison process to compare it with the authorized fingerprint image.

Putluru Sravani and kannapan proposed a High security door lock system by using Android mobile with Bluetooth [8]. Once wireless communication between Smartphone Bluetooth and Bluetooth module is established through a pairing process, user's key selections are sent as radio frequency (RF) signal to the main controller board installed at home. Then the Arduino Uno controller is used to interpret key selections and determine whether to release or not the electromagnetic (EM) lock home door.

The limitation of this project is that Bluetooth has slower data transmission rate when compared to other hardware interfacing technologies. Its range of connectivity is very short so the user must remain close to the door to get accessed. Shruti Koza et.al proposed Password Based Door Lock System for home security [9]. Here an electronic 
code lock system is made using Arduino UNO, which provides control to the actuating load.

If you forget the password it is not possible to open the door because multiple attempts are not provided for the users to access the door. Md.Maksudur Rahman,M. Sowket Ali and Md. Shoaib Akther proposed Password Protected Electronic Lock System for Smart Home Security [10]. An electrical lock allows activation of an electrical appliance on entering the correct password. PIC18F452 micro controller plays the role of the processing unit. The MCU is interfaced with a $4 * 4$ matrix keypad and a $16 * 2$ LCD to the user interface. It does not provide a strong identity check because it is only based on a password. Ketan Rathod,et.al proposed Smart door security using Arduino and Bluetooth Application [11]. Arduino along with HC-05 and mobile Applications allows us to control door from anywhere in the home and constantly keep watch on it. R-Pi would exchange data or would communicate with the help of Bluetooth, Wi-Fi and Ethernet.

When the access is verified by the user the lock is opened. The limitation is that System implementing must requires WIFI/Ethernet for the data communication. It is not possible to place connected devices in a certain range to get access or else it results in failure. Hasem abdo Qasem Saeed Al-Nabhi proposed a Fingerprint based security system[12]. The limitation with the smart lock is that, if the battery drains off, you will have to face a lot of hassle to gain access to your premise.AkashSDevadiga,et.al proposed Smart Door Control System [13].

The system mainly consisting of micro controller, GSM and gear motor for controlling the door. A GSM modem provides the communication interface. The limitation of the project is that when there is no network available or poor network connectivity then the system cannot be accessed. Martin Magdin and Stefan Koprda proposed Biometric Authentication of Fingerprint with Using Fingerprint Reader and Micro controller Arduino [14]. The main part of this system is the micro controller Arduino Uno with an external interface to scan for the fingerprint with a name Adafruit R305. This microcontroller communicates with the external database, which ensures the exchange of data between Arduino uno and user application.

Adarsh V Patil,et.al proposed Android Based Smart Door Locking System [15]. The RFID card reader detects and checks the user accessibility. HC-05 module is an easy to use Bluetooth SPP module, designed for transparent wireless serial connection setup. The limitation related to smart locks regards a sudden blackout of the control unit or a fault of the recognition device. In both cases, the risk is that you cannot enter your house because the system is unable to authenticate you for accessing the premises.

From the literature review that has been discussed, there are few researchers that discuss the home security and remote door. Therefore we make a research that can control the door remotely, receive alerts and grant a door access to the people whose identification is stored on the database. The big difference between the related works and the system we proposed are that our system has multiple layer of security like OTP and user validation which provides the user feel secured. This makes smartphones a suitable platform for uses beyond making and receiving phone calls. Combined with the ability to perform short-range wireless communications via Bluetooth, the smartphone is like to like replacement for physical keys. 


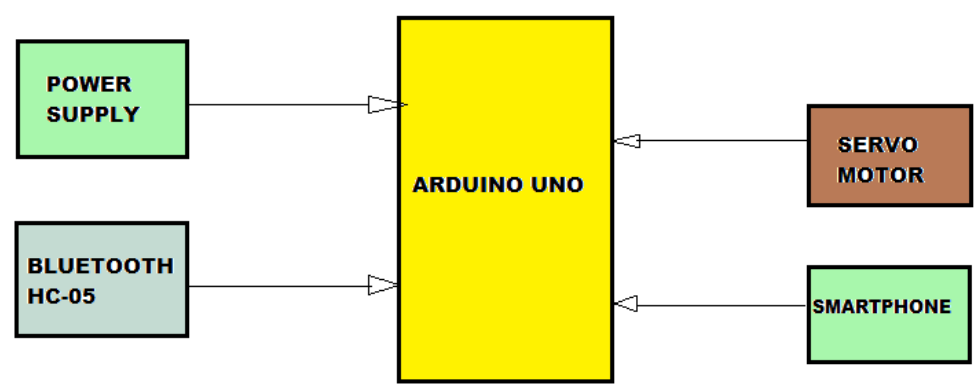

Figure 1. Block Diagram

\section{System Architecture}

The proposed system mainly consists of Arduino uno, Bluetooth HC-05 and Servo motor. Arduino uno acts as the micro controller in this system which operates the overall function. Bluetooth allows the user to connect the system with the application, so that the message can be passed to the system. Power supply is given to the system by means of USB connection or with external power supply so that the system works efficiently without any interruption. When the door wanted to be unlocked the user must login to the application and then an OTP will be shared to their registered mobile number. After the verification process the user need to place their finger on the fingerprint button. And then the door gets unlocked.

\subsection{System Modules}

Bluetooth wireless module is utilized in a master/slave management. In our wireless biometric lock, the $\mathrm{HC} 05$ module plays a important role by pairing with mobile fingerprint. By the use of $\mathrm{HC} 05$ module only the lock opens. By default, the processing plan setting is slave. The role of the module can be designed distinctly by at commands. The slave modules cant start an association with another Bluetooth gadget, yet can knowledge connections. Master module can establish connection with different gadgets.

Arduino Uno is an open source micro controller based on the micro chip AT mega 328P micro controller and developed by Arduino.cc. via USB cable it can be given connections with Jumper wires to unlock the wireless biometric lock. It accepts voltages between 7 and 20 volts. It is similar to the Arduino nano and leonardo. Layout and production files for some versions of the hardware are also available. 


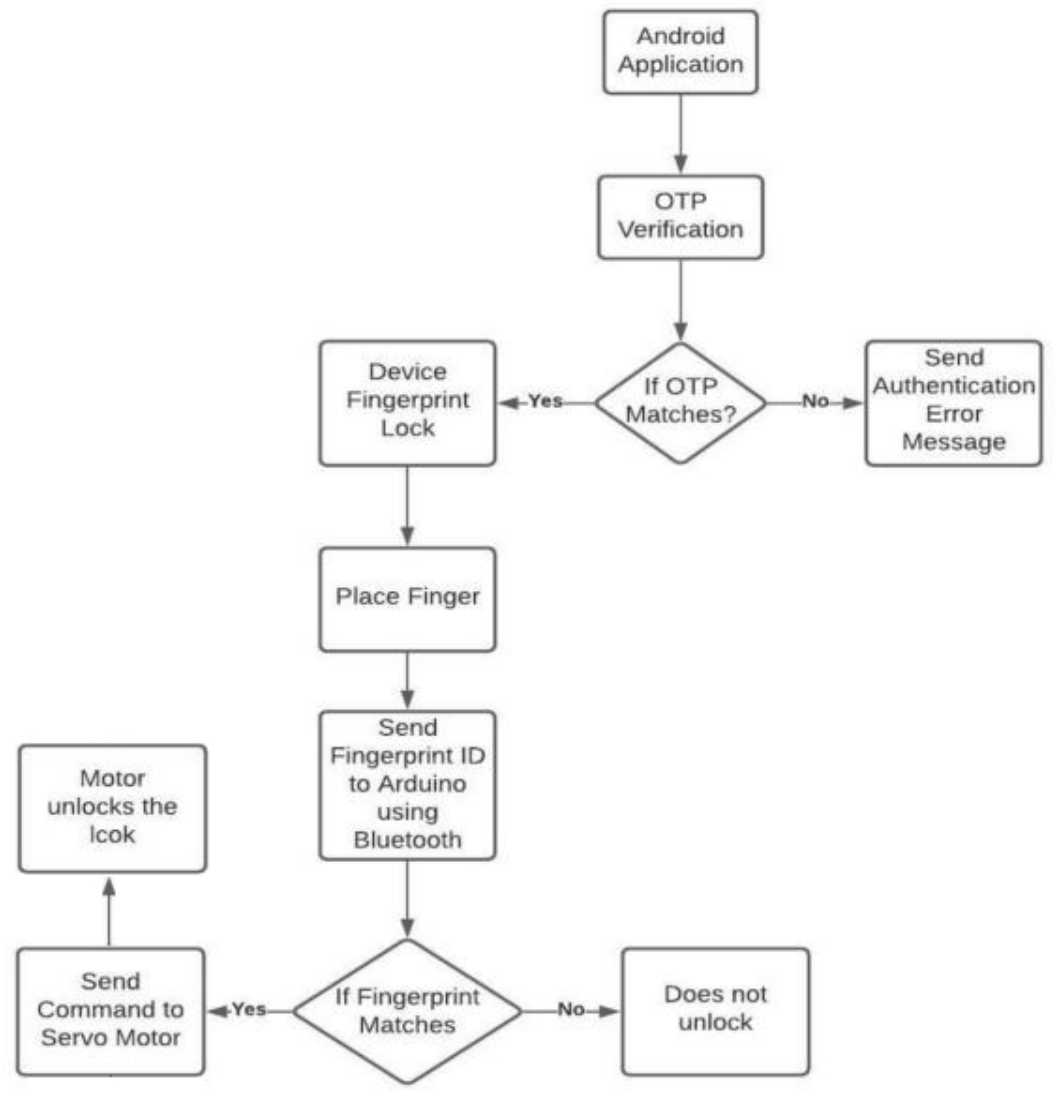

Figure 2. Data Flow Diagram
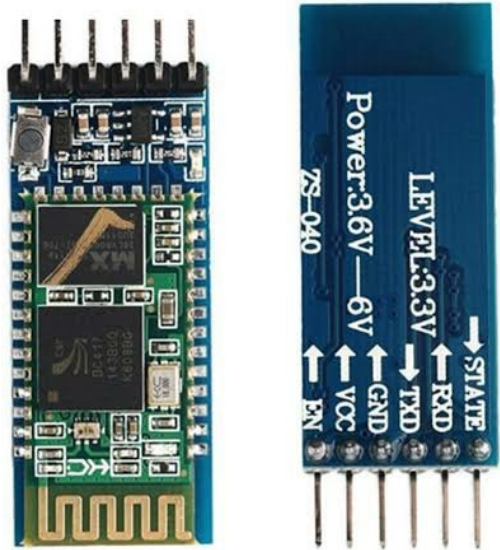

Figure 3. Bluetooth HC-05 module

Servo motors are utilized in application, For example, mechanical technology, CNC apparatus or mechanized assembling. They are commonly utilized as a superior option in 


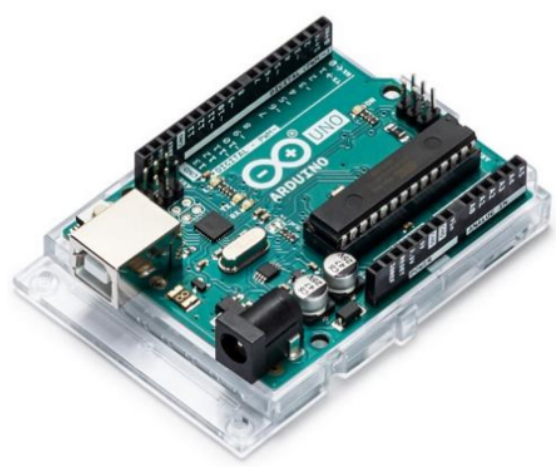

Figure 4. Arduino UNO Module

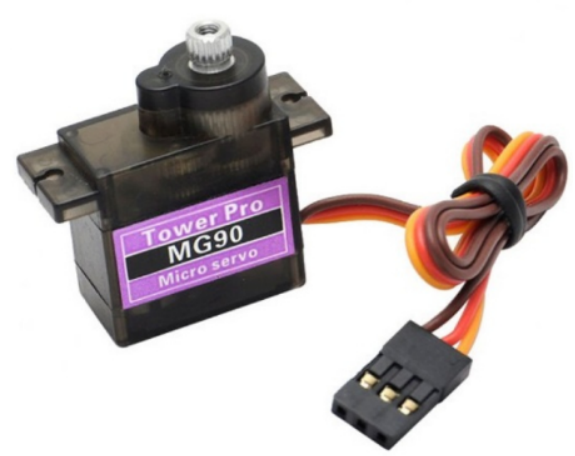

Figure 5. Servo Motar Module

contract of the stopper engine. They have inherent yield steps. The encoder and regulator of a servo motor are an extra expense, yet they advanced the presentation of the general frame work. This can be seen when turning on an ink jet printer.

\section{Implementation}

Use of Firebase in this project adds an extra security layer to the system. The user of the system can view who are the persons and their mobile numbers that are logged in the application. When an unauthorized person tries to access the door they will get a notification. The user has the power to disable the unauthorized person mobile number. Therefore the unauthorized persons cannot be granted access to the system. The initial step

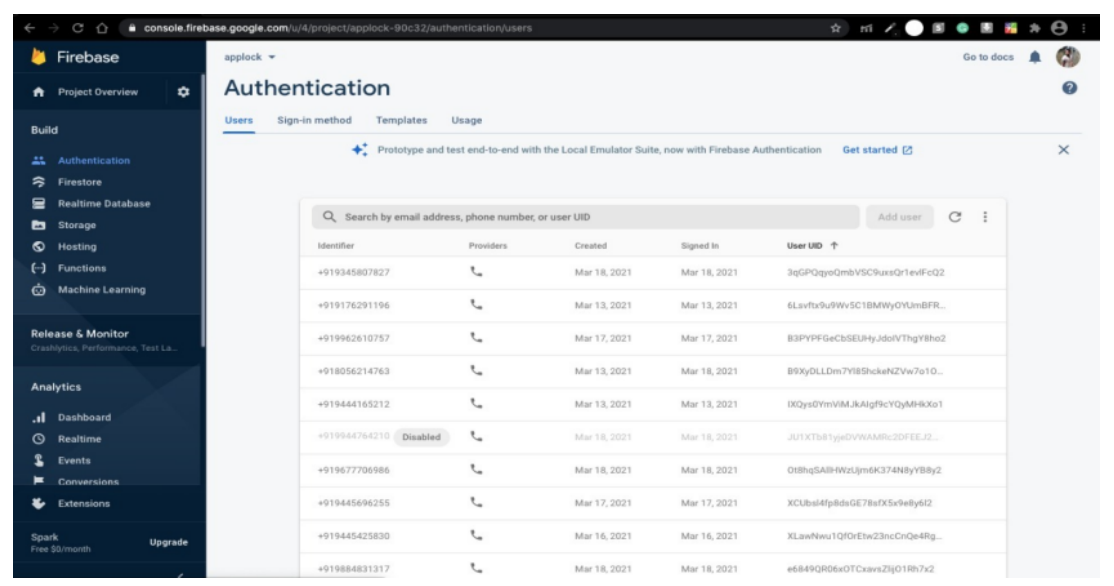

Figure 6. Monitoring of User Access

is to create a program using Arduino IDE and uploading it into the Arduino Uno. This program creates communication between the Arduino and the smartphone via bluetooth. Next step is to create a string variable which stores the unique device ID for the lock. To receive the data sent by the phone we use bluetooth HC-05 module. Next is to create 
a Loop function that stores the device ID. Then an if condition is used for verifying the sent ID by the bluetooth. When the fingerprint of the user is scanned by the smartphone it initially authenticates with the one present in the application. After the authentication, the application sends the device ID to the Arduino board. In the event this ID matches with the one set in Arduino, at that point the servo motor moves the lock to open position.

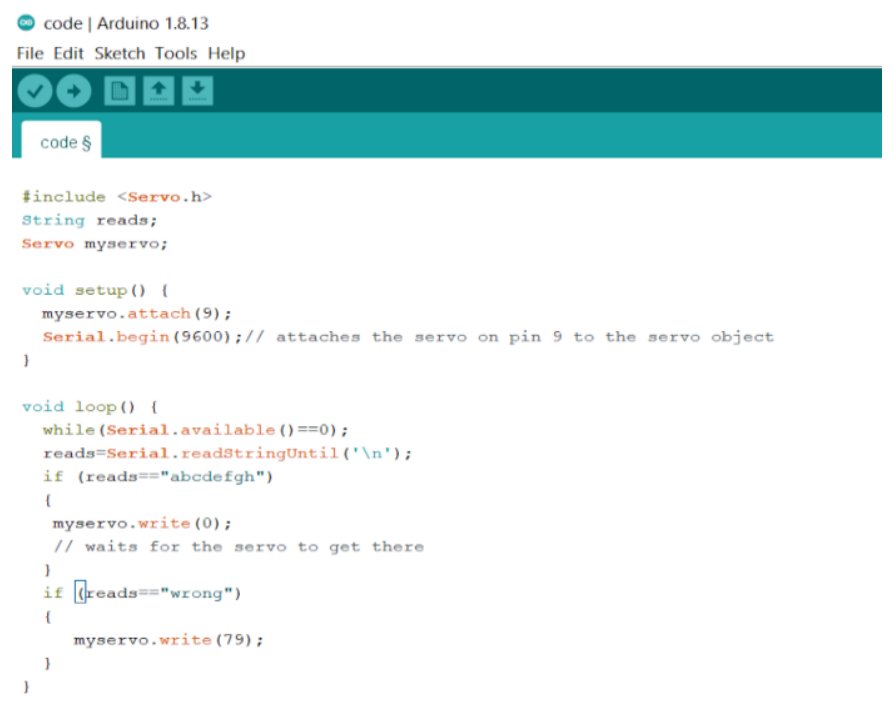

Figure 7. Arduino IDE Interface.

\section{Result and Analysis}

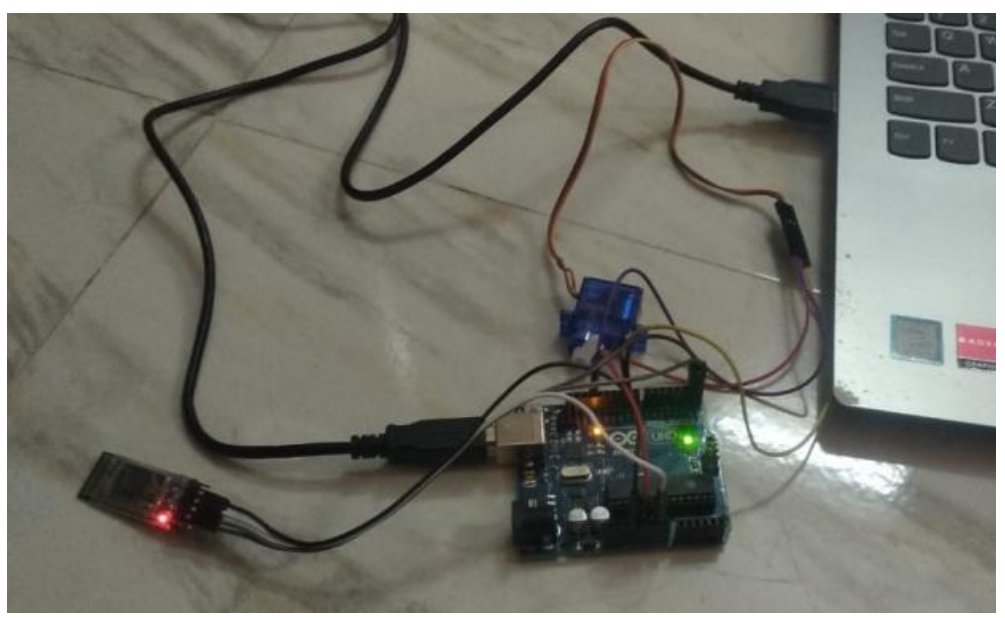

Figure 8. Working Model. 
Initially we need to connect our phones with the system by the application which we created on Kodular. Once we get connected we will be able to lock or unlock the door using the scroll button in the application. If we place our fingerprint on the unlock position then the application will send a particular value to the Bluetooth module and then the servo motor will rotate with a certain degree so that the door will be opened. When the person wants to access the door first they have to pair their smartphone to the system. Then the application collects information like a mobile number and then it sends the message to the person who wants to access the door. Once the OTP is verified the door will be unlocked for the user. The user can view the unauthorized person who tried to access the door and can stop them by disabling the unauthorized users. Compared to other systems our system has another layer of security in the form of Bluetooth password.



Figure 9. Auth Control Interface.

The user can view who are all the persons that have logged in the system by using Firebase. If we place our fingerprint again on the position then the value is fetched and sent to Arduino via Bluetooth module $\mathrm{HC}-05$ and then the servo motor is rotated with the 
value and then the door gets unlocked. The result efficiency of the proposed system has a higher result rate compared to other existing systems mainly due to the whole system works under a simple algorithm called matching algorithm, which is used to compare previously-stored templates of fingerprints against user's fingerprints for authentication purposes.

\section{Conclusion}

The proposed system helps in implementing a design for home security using Arduino Uno and Bluetooth module. Our system is cost effective compared to the available lock systems on the market. Our fingerprint lock system has a high accuracy rate and seamless integration with the users and provides maximum security. It is designed in a modern way that a normal person can use. It is very compact in size and easy to integrate. The mobile application used here is also very simple and easy to use interfaces where they can easily interact with application to use the wireless biometric lock.

\section{References}

[1] Patil KA, Vittalkar N, Hiremath P, Murthy MA. Smart door locking system using IoT. Int Res J EngTechnol (IRJET). 2020;7(5):3090-4.

[2] Firdosh S, Shikha PK, Durgam B, Begum N, Singh SK. Password based door locking system using microcontroller. International Journal of Scientific Research in Computer Science, Engineering and Information Technology, IJSRCSEIT. 2017;2:1-5.

[3] David OA, Chinaza M, Jotham O. Design and implementation of a door locking system using android app. International Journal of Scientific \& Technology Research. 2017;6(8):198-203.

[4] Varughese SE, George M, Anand J. Content Based Image Retrieval Technique on Texture and Shape Analysis using Wavelet Feature and Clustering Model. International Journal of Enhanced Research in Science Technology \& Engineering. 2014 Aug;3(8):224-9.

[5] Paul P, Al Achib MA, Hossain HS, Hossain MK. Smart Door Lock Using Fingerprint Sensor. BRAC University. 2019:1-13.

[6] Rao BV, Chaitanya PA, ruchitha Reddy A. Smart Door Unlock System using Fingerprint. Pramana Research Journal. 2019;9(3):756-61.

[7] Baidya J, Saha T, Moyashir R, Palit R. Design and implementation of a fingerprint based lock system for shared access. In2017 IEEE 7th Annual Computing and Communication Workshop and Conference (CCWC) 2017 Jan 9 (pp. 1-6). IEEE.

[8] Sravani P, Knnappan S. High Security Door Lock System by Using Android Mobile with Bluetooth.

[9] Prabhakar AY, Oza SK, Shrivastava N, Srivastava P, Wadhwa G. Password Based Door Lock System. International Research Journal of Engineering and Technology (IRJET). 2019 Feb;6(2):1154-7.

[10] Rahman MM, Ali MS, Akther MS. Password Protected Electronic Lock System for Smart Home Security. International Journal of Engineering Research and Technology. 2018;7(4):541-4.

[11] Rathod K, Vatti R, Nandre M, Yenare S. Smart door security using Arduino and Bluetooth application. International Journal of Current Engineering and Scientific Research (IJCESR). 2017 Nov;4(11):73-7.

[12] Anand J, Flora TA, Philip AS. Finger-vein based biometric security system. International Journal of Research in Engineering and Technology eISSN. 2013 Dec;2(12):197-200.

[13] Anand KJ, Sivachandar K. An edge vector and edge map based boundary detection in medical images. International Journal of Innovative Research in Computer and Communication Engineering. 2013 Jun;1(4):191-3.

[14] Martin M, Štefan K, L'ubor F. Biometrics Authentication of Fingerprint with Using Fingerprint Reader and Microcontroller Arduino. Telkomnika. 2018 Apr 1;16(2):755-65.

[15] Patil AV, Akshay S, Patgar C, Prakash S, AJ SK. Android Based Smart Door Locking System. International Journal of Engineering Research \& Technology (IJERT). 2018;6(13):1-4. 